\title{
"UNSTABLE SPATIAL DIFFERENCES OF THE GEOMAGNETIC ELEMENTS CAUSED BY CHANGING WATER SATURATION OF A VOLCANIC SEDIMENT,
}

\author{
András Csontos* ${ }^{*}$, , Péter Kónya ${ }^{1}$, György Falus ${ }^{2}$, Anikó Besnyi ${ }^{1}$ \\ (1) Mining and Geological Survey of Hungary, Budapest, Hungary \\ (2) Eötvös Loránd University, Budapest, Hungary
}

Article history

Receveid December 29, 2016; accepted February 15, 2019.

Subject classification:

Effect on internal geomagnetic field; Rock magnetism; Magnetic anomalies; Volcanic sediments; Observatory practice; Water saturation.

\begin{abstract}
Since the beginning of geomagnetic recording at Tihany Geophysical Observatory, baseline instability has been observed, especially in the case of the old variation house. The regularly observed annual baseline change is independent from the type of magnetometer used. Common environmental effects on the instruments (for example temperature effects) are not suitable to characterize this variation. A possible reason of this instability is an unconventional geomagnetic effect on the magnetic properties of the sediment. The water saturation of a lake mud in a geyser cone shows correspondence with the variation of the base values. X-ray powder diffraction measurement detected different type of magnetic minerals in the lake mud. In this study we present a possible source and the mechanism of the effect.
\end{abstract}

\section{INTRODUCTION}

Although, the systematic geomagnetic recording have been restarted in 1949 at a temporary station in Hungary, the need for a permanent observatory was strongly felt during the 1949-50 geomagnetic base network measurements. The search for a place void of actual and possible future industrial disturbance led to the selection of Tihany national park on the peninsula of Lake Balaton. This peninsula is characterized by the presence of two lakes: the Inner Lake and the Outer Lake. The territory of the Outer Lake is nearly one square kilometers. The surface of the Inner Lake is approximately one third of the Outher Lake. The depth of the lakes is 1,5 meter on average (Figure 1).

The construction work of the observatory started in 1952 and was completed in 1954 by Eötvös Loránd Geophysical Institute of Hungary (ELGI). The scientific prepa- ration, and the building project itself, were headed by György Barta (1915-1992), who later became the first leader of the observatory. Tihany Geophysical Observatory has continuously recorded geomagnetic data since the year 1955 [Csontos et. al 2007].

The buildings of the observatory were constructed according to the technical level of the 1950's. The houses for magnetic observations are built of iron-free stones and, as much as possible, non-magnetic materials. Since the beginning, any necessary modernizations have been performed from time to time. The environment of the buildings and pillars was repeatedly tested. In $1991 \mathrm{sev-}$ eral significant artificial anomalies, i.e. iron polluted pillars and cables, were removed from the buildings and from the grounds of the observatory.

The variometer measurement house (variation house [Wienert, 1970]) was constructed in accordance with the 


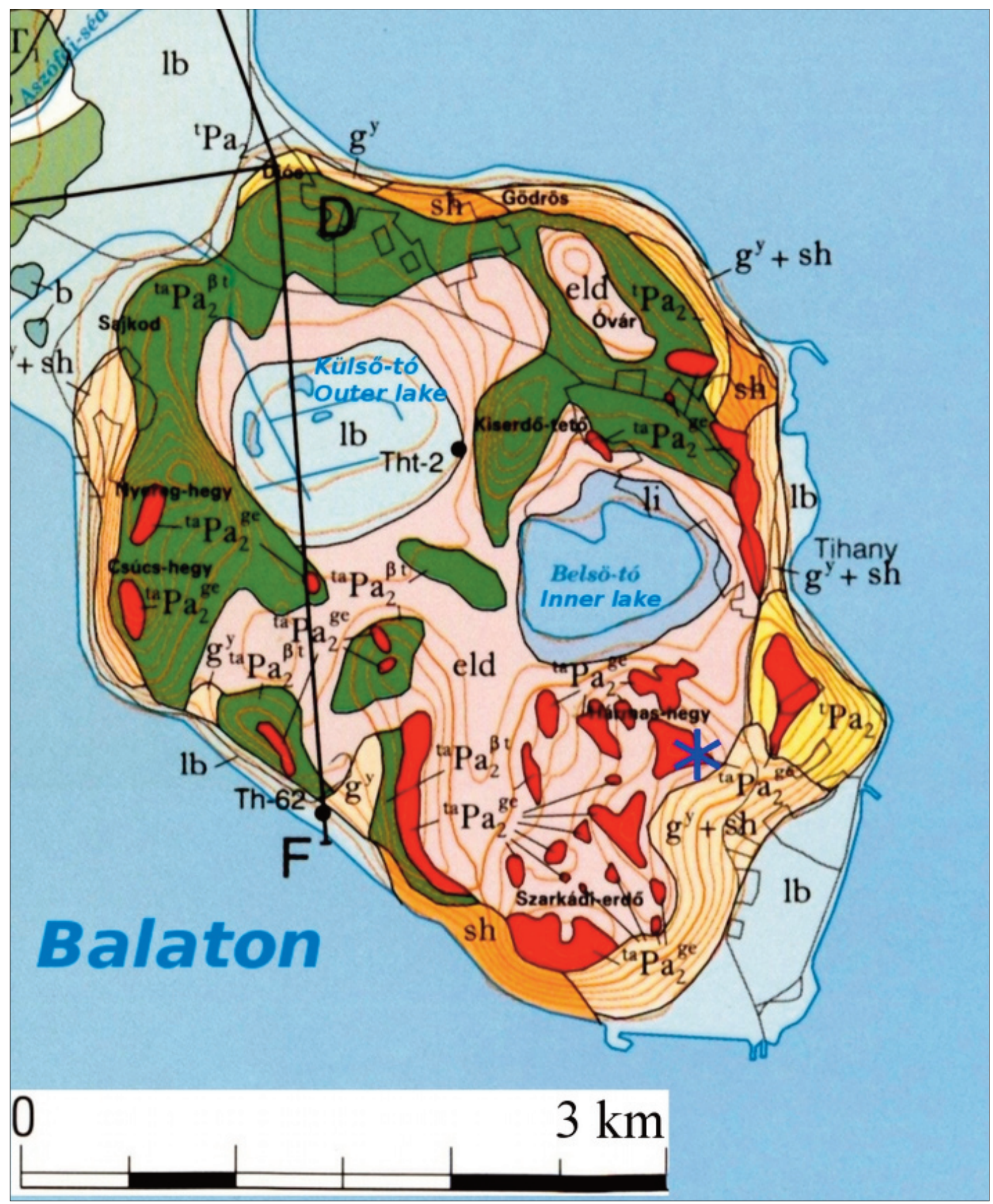

FIGURE 1. The diagram shows Tihany's geological characteristics. The green areas represent volcanic rock and the red patches show geysers. The blue asterix shows the grounds of the observatory [Budai et al., 1999].

needs of classical instruments, for instance analogue photo recorders. To reduce the effect of daily and seasonal temperature variation, the rooms are underground and a thatched roof covers the cellars. This cellar was built on the clayey area about 40 meters away from the absolute measurement house (absolute house [Wienert, 1970]) of the observatory. The difference in the elevation between the pillars of the two sites is of about 5 meters. The absolute house was built on an apex of Cser-hegy (Cser hill) to ensure a vantage-point for az- 
imuth observation. Cser- hill is one of the peninsula's cone geysers [Barta 1956]. Since 1999 onward an FGE fluxgate magnetometer has been used as the main recording system of the observatory. This device was installed in a new pavilion. This hut is in the upper and rocky part of the observatory grounds. (Figure 2) the variometer. Observers should monitor the development of the base values. In this way the observatory is able to provide absolute controlled geomagnetic records. By this procedure a higher level of the geomagnetic observation is established.

The induction effects on sediments with high con-

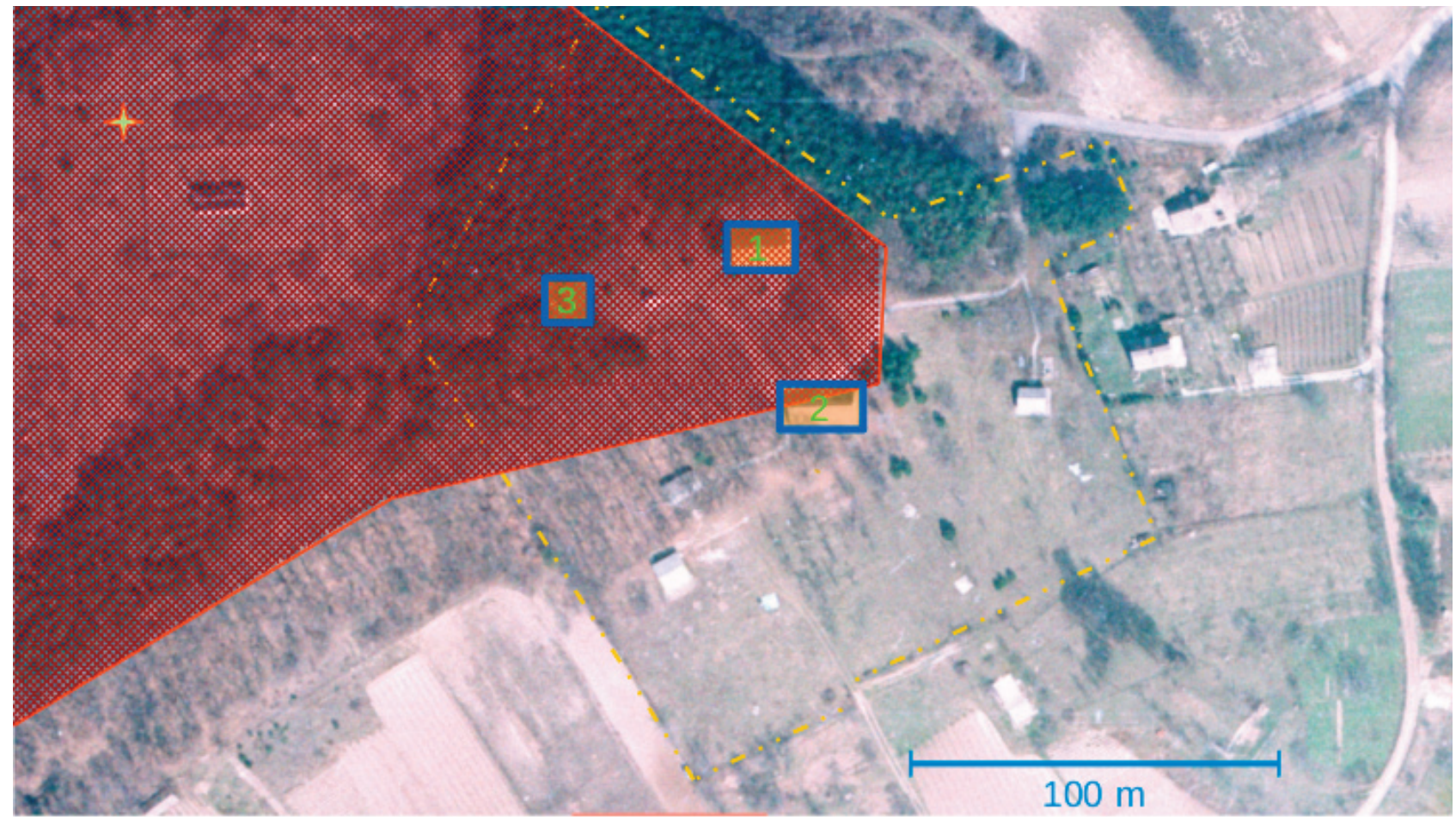

FIGURE 2. The aerial photo shows environment of the observatory. The yellow lines mark the fence of the ground. The marked area presents the actual section of the geological map where the geyserite was deposited. The yellow asterisk marks the top of the Cser hill. 1 marks the absolute house, 2 marks the old variation house, 3 marks the new pavilion for variometers.

The direction and the intensity of geomagnetic elements are measured in many ways in current observatory practice. Several of the methods implicitly assume that the area of observation should be free from vertical and horizontal gradients, in practice the gradients of the geomagnetic elements between the pillars should be less than $1 \mathrm{nT} / \mathrm{m}$ [Jankowski and Sucksdorff, 1996]. This assumption creates the expectation that all measurements at the observatory should reduce to the absolute pillar. If the observers knew the differences (which are considered to be constant values) of geomagnetic elements between the pillars, they could perform this task. In order to improve the reliability of geomagnetic recordings, absolute measurements are taken regularly on the absolute pillar. The result of absolute measurements is theoretically free from every possible instrumental error. The difference between the result of the absolute measurement and the synchronous record of the variometer is the base value of ductivity contrast caused by external magnetic fields were repeatedly studied before. Influence of induction was observed generally in magnetic recordings as a result of the high conductivity contrast of different materials. Indeed, the gradients of the geomagnetic elements are not constant regions affected by induction effects and their fluctuations depends on the frequency of the geomagnetic variations. It fallows that, in presence of conductivity contrasts in the area of the observatory the accuracy of the absolute control of a variometer is decreased, because the base values of a variometer become dependent on the influences of external magnetic fields [Csontos, 2012].

Based on the observation of Tihany baseline instability, that will be shown to be independent of the type of magnetometer used for geomagnetic measurements, this article describes the influence of an unconventional hydrological effect on the magnetic properties of the sediment and hence on the crustal geomagnetic field. 
Indeed, it will be shown that this hydrological effect is the cause of the instability of the geomagnetic gradient observed in the old variation house and that this instability has no direct connection with the time-varying magnetic field induced by ionospheric and/or magnetospheric currents. We will also present the steps to isolate the possible sources.

\section{GEOLOGICAL AND GEOPHYSICAL BACK- GROUND}

\subsection{GEOLOGICAL DEVELOPMENT OF TIHANY PENIN- SULA}

When volcanism began approximately 7-7.5 million years ago, the area might have been a marshy alluvial plain with large open-water surfaces. In the first phase of the volcanic activity eruptions likely occurred at the center of the present-day peninsula [Hoffer, 1943]. The basalt lavas rising to the surface came into contact with the water-filled layers of Pannonian sandstone. The large quantity of produced gas caused massive phreatic explosions. The high-energy eruptions in the centre of the Tihany Peninsula finally resulted in the formation of maars. Maar formation is typical sign of phreatomagmatic eruptions. At the onset of the eruption, magma began to interact with a moderate amount of ground water in the water-saturated sand beds [Németh et al., 2001].

As eruption continued, the crater grew and the phreatomagmatic blasts fractured the deeper (harder, consolidated) rock facies around the down-migrating explosion focus, giving free way for the karst water to the explosion chamber. During the blast the volcanic cloud was unlikely to have been particularly high; the majority of the process was driven by pressure from below (resulting in amorphic tuffs at low temperatures). In the next stage, a new vent developed in the western side of the peninsula, around the Csúcs-hegy (which is a highest hill of the present-day peninsula). In this new maar crater, a thick reworked maar-lake turbidity deposit pile developed with thick freshwater carbonate laminae. In the third stage, when the center of the eruption migrated to the interior of the peninsula, active vent systems fed small Strombolian, then Hawaiian scoria- and spatter cones.

These scoria deposits were the source of the continuously building Gilbert-type delta fronts in the nearby maar craters [Németh et al., 1999]. Only after the vol- canic activity had ended, the heat of magma trapped at depth was still heating its surroundings for thousands of centuries. High temperature gases $\left(\mathrm{CO}_{2}, \mathrm{SO}_{2}\right)$ coming from the molten basalt streamed upwards trough the rock fractures and mixed with the underground waters. These hot waters occluded the gases, and thus became aggressive, dissolving calcium, silica, magnesium and iron from sedimentary rock and depositing them on the surface in the form of hot spring cones.

The name of the deposit is geyserite. (see Figure 1 for more details.) The intensive hydrothermal activity the geysers - really sprang into life and their eyecatching legacy is manifested in the present-day geyser cones. Once volcanic activity ceased, the gradual process of erosion began [Lóczy, 1913].

\subsection{RESULTS OF SOME GEOPHYSICAL MEASURE- MENTS PERFORMED ON THE TIHANY PENIN- SULA}

Before the foundation of the observatory, magnetic measurements were performed on the peninsula. In October of 1952 a network was established with a station spacing of 500 meters. According to the survey the NW-part of the peninsula showed the existence of anomalies of volcanic rocks but in the SE region, the spatial variation of the geomagnetic field was weak [Annual report of Tihany observatory in the years 1955-56].

In 1963 the peninsula was surveyed again by ELGI. In this campaign not only magnetic but also gravity measurements were performed. The network was in this case more extensive; a lot of readings were taken on the frozen surface of Lake Balaton. The result of this campaign provided a good basis to develop a geophysical model of the geological structure of the area [Bender et al., 1966].

In 2004 a new magnetic survey was carried out in the peninsula on a grid with a spacing of 200 meters by ELGI and Eötvös Loránd University. Later detailed measurements were made along irregular lines in the area of the Outer Lake, because the highest amplitude anomaly was found there.

Overhauser magnetometers and GPS were used to achieve the best accuracy [Lipovics et al., 2004]. The $1000 \mathrm{nT}$ anomaly found beneath the Outer Lake was attributed to a basalt dyke or basaltic tuff formations extending downwards for several hundred meters.

This is probably the remanent of the main maar crater. 


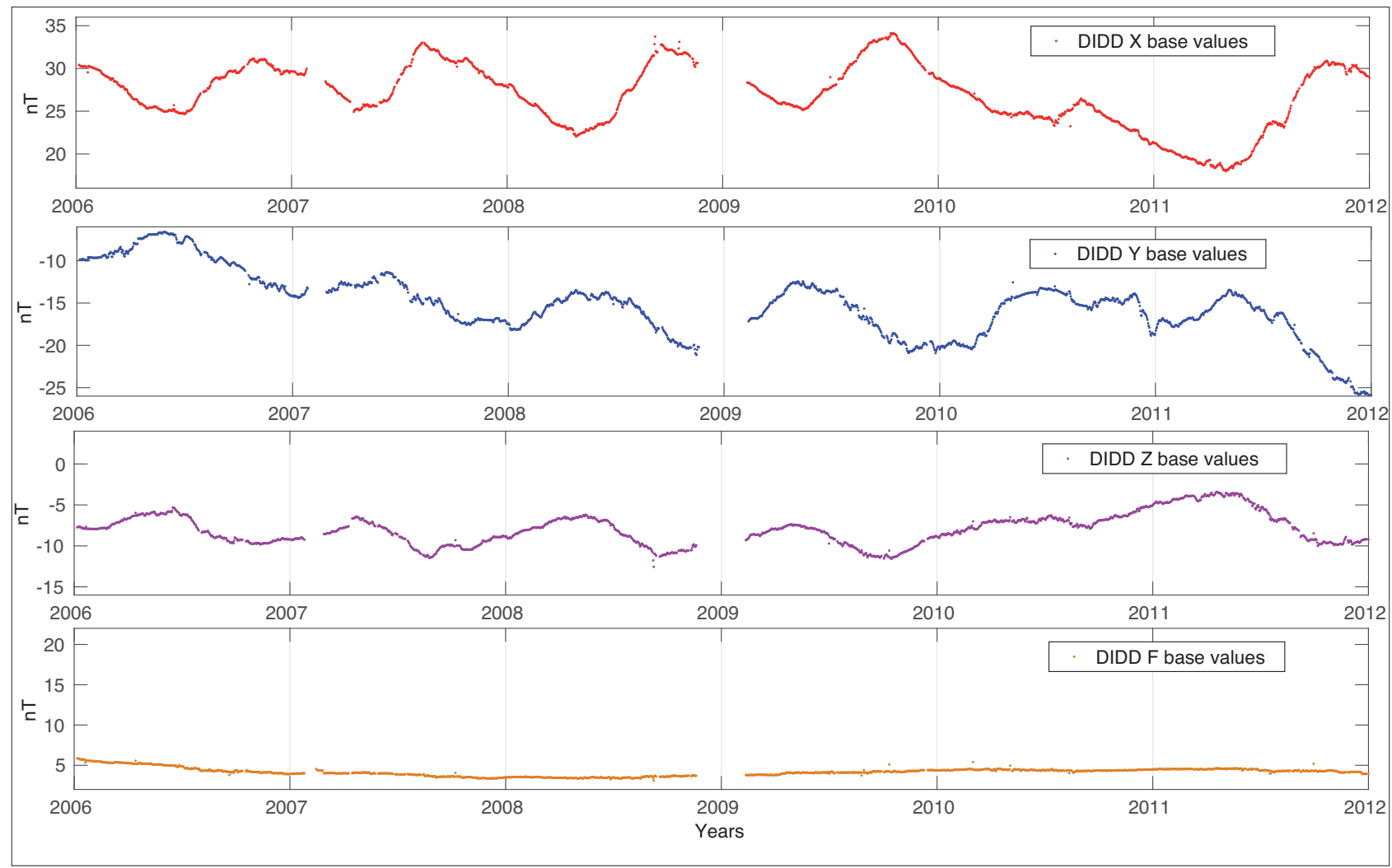

FIGURE 3. X, Y, Z and F base values of DIDD 2006-2011 (difference between the measured and the definitive daily mean values of corresponding components).

\section{GEOMAGNETIC EFFECT AS SEEN ON DIF- FERENT TYPES OF MAGNETOMETERS}

\subsection{LA COUR ANALOGUE INSTRUMENTS AND LEMI FLUXGATE MAGNETOMETER}

Since the beginning of the measuring activity in the observatory, the baselines of the variometers have displayed an unusual behavior. The La Cour instruments (well-known analogue photo recorders for recording the variation of the horizontal and vertical component of the geomagnetic field as well as the magnetic declination with independent devices) were installed in the variation house. Below we present here the results from the determination of the sensor's temperature coefficients (Table 1).

The seasonal variation due to the effect of temperature on the device was realized just after the start of the continuous recording. On the other hand the variation of temperature coefficients presented seasonal differences during those years. As a consequence of the high temperature sensitivity of La Cour magnetometers, this kind of instrumentation was not suitable to confirm the appearance of any effect [Annual report of Tihany observatory in the years 1955-56]. From 1990-1998 a LEMI fluxgate device was installed in a temperature controlled room of the vari-

\begin{tabular}{|c|c|c|c|}
\hline $\begin{array}{l}\text { Year: } \\
1955\end{array}$ & $\begin{array}{c}1^{\text {st }} \text { Jan. }-29^{\text {th }} \\
\text { June }\end{array}$ & $\begin{array}{l}30^{\text {th }} \text { June - } \\
17^{\text {th }} \text { Sept. }\end{array}$ & $\begin{array}{l}18^{\text {th }} \text { Sept. - } \\
31^{\text {th }} \text { Dec. }\end{array}$ \\
\hline $\begin{array}{c}\text { Temp. coeff. of } \\
\mathrm{H}\left(\mathrm{nT} / \mathrm{C}^{\circ}\right)\end{array}$ & 13,7 & $-8,5$ & $-0,6$ \\
\hline Year: 1956 & $\begin{array}{c}25^{\text {th }} \text { Jan. }-2^{\text {nd }} \\
\text { Mar. }\end{array}$ & $\begin{array}{c}3^{\text {rd }} \text { Mar. }-12^{\text {th }} \\
\text { Sept. }\end{array}$ & $\begin{array}{l}13^{\text {th }} \text { Sept. - } \\
31 \text { th Dec. }\end{array}$ \\
\hline $\begin{array}{c}\text { Temp. coeff. of } \\
\mathrm{H}\left(\mathrm{nT} / \mathrm{C}^{\circ}\right)\end{array}$ & 6,5 & 0,5 & 2,8 \\
\hline
\end{tabular}

TABLE 1. The adopted temperature coefficients of the H sensor of La Cour recording instruments in the years 1955 and 1956 (Annual report of Tihany observatory in the years 1955-56).

ation house. The suspended sensor of the device automatically eliminated the tilt of the pillar. Although, the long term baseline variation was more stable compared to the La Cour instruments', the typical annual period of base values was permanently observed. The typical range of the yearly baseline variation was $20 \mathrm{nT}$ and we could notice the opposite trends in $\mathrm{X}$ and $\mathrm{Z}$ components. The extreme values were observed usually in May and in October. Other instrumental effects are also a possibility (INTERMAGNET CD). The focus of our study is the dataset of a DIDD in- 


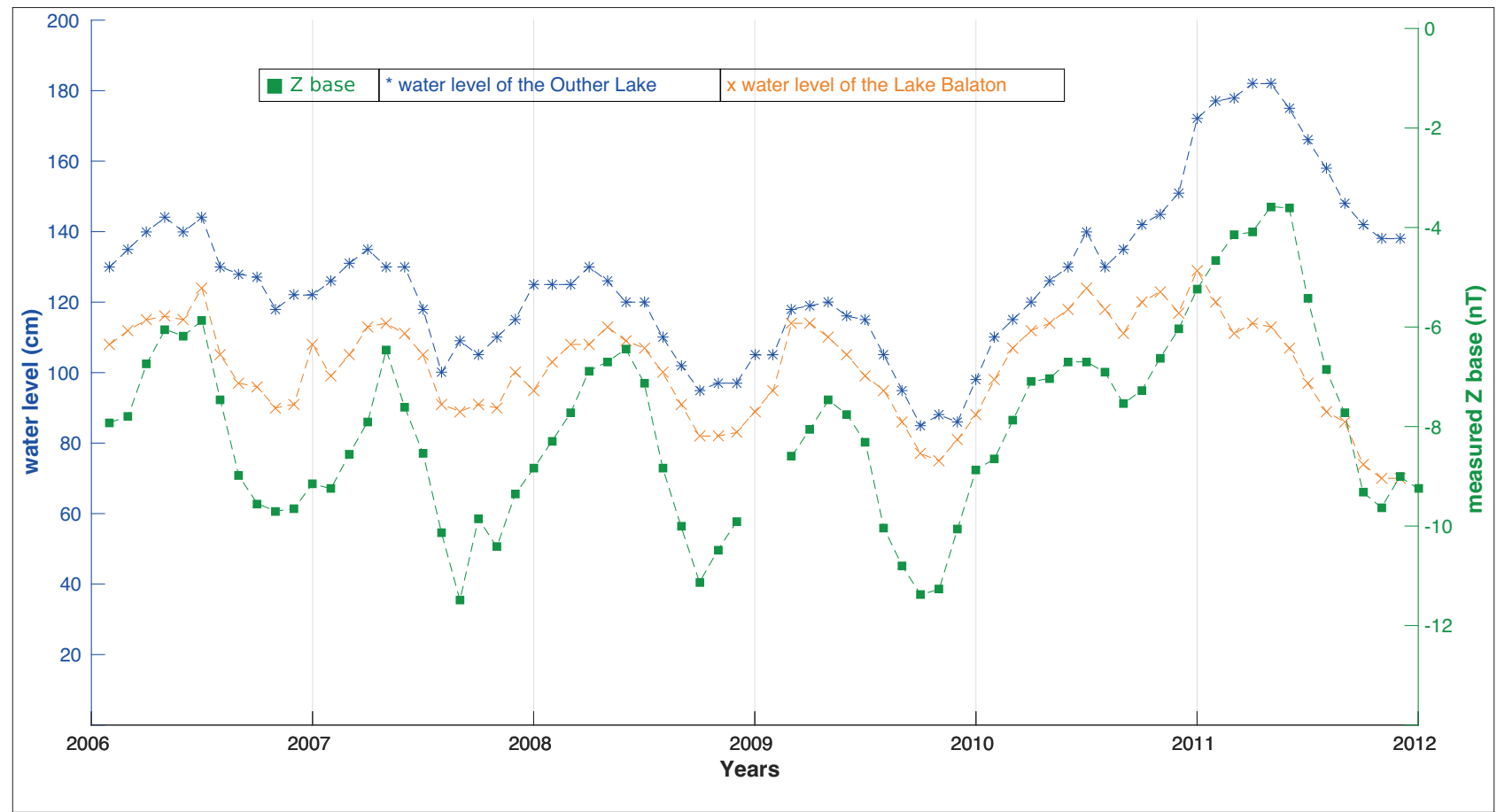

FIGURE 4. The monthly mean values of DIDD Z baseline (green), the water level of Lake Balaton (orange) and the water level of Outer Lake (blue) 01.2006-12.2011.

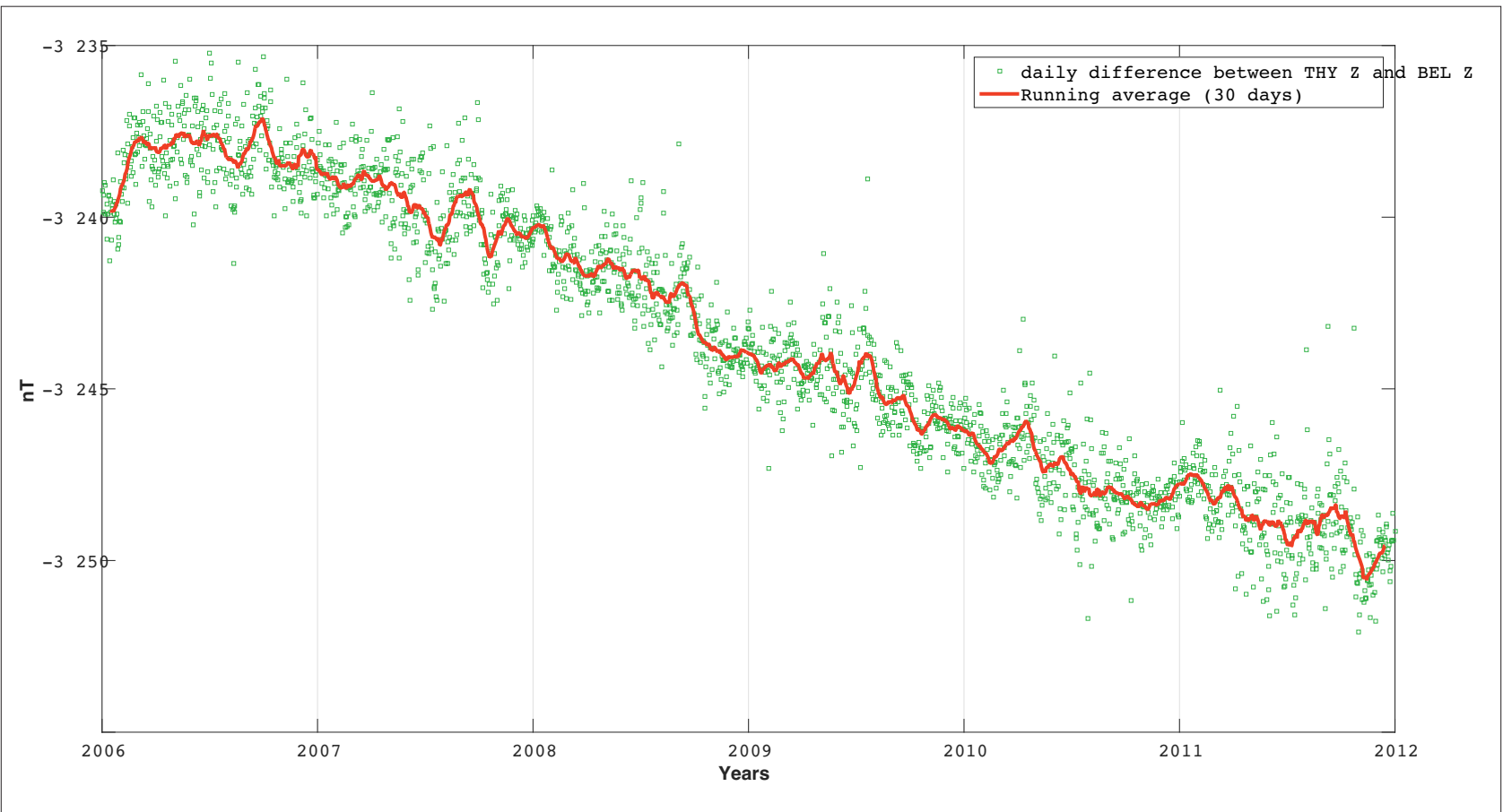

FIGURE 5. The difference between (THY Z-BEL Z) (green) and the running average (red) calculated from the daily mean values 01.01.2006.-31.12.2011.

strument which is a vector magnetometer based on Overhauser effect. Before the detailed analysis of the longterm base values of DIDD we can conclude that the regularly observed annual baseline change is independent from the type of magnetometer used.

\subsection{DIDD MAGNETOMETER}

A DIDD magnetometer was installed in 1999 in the same room of the variation house as the previous devices before it. The room was not temperature controlled. The long term baseline variation (Figure 3) cannot be ex- 


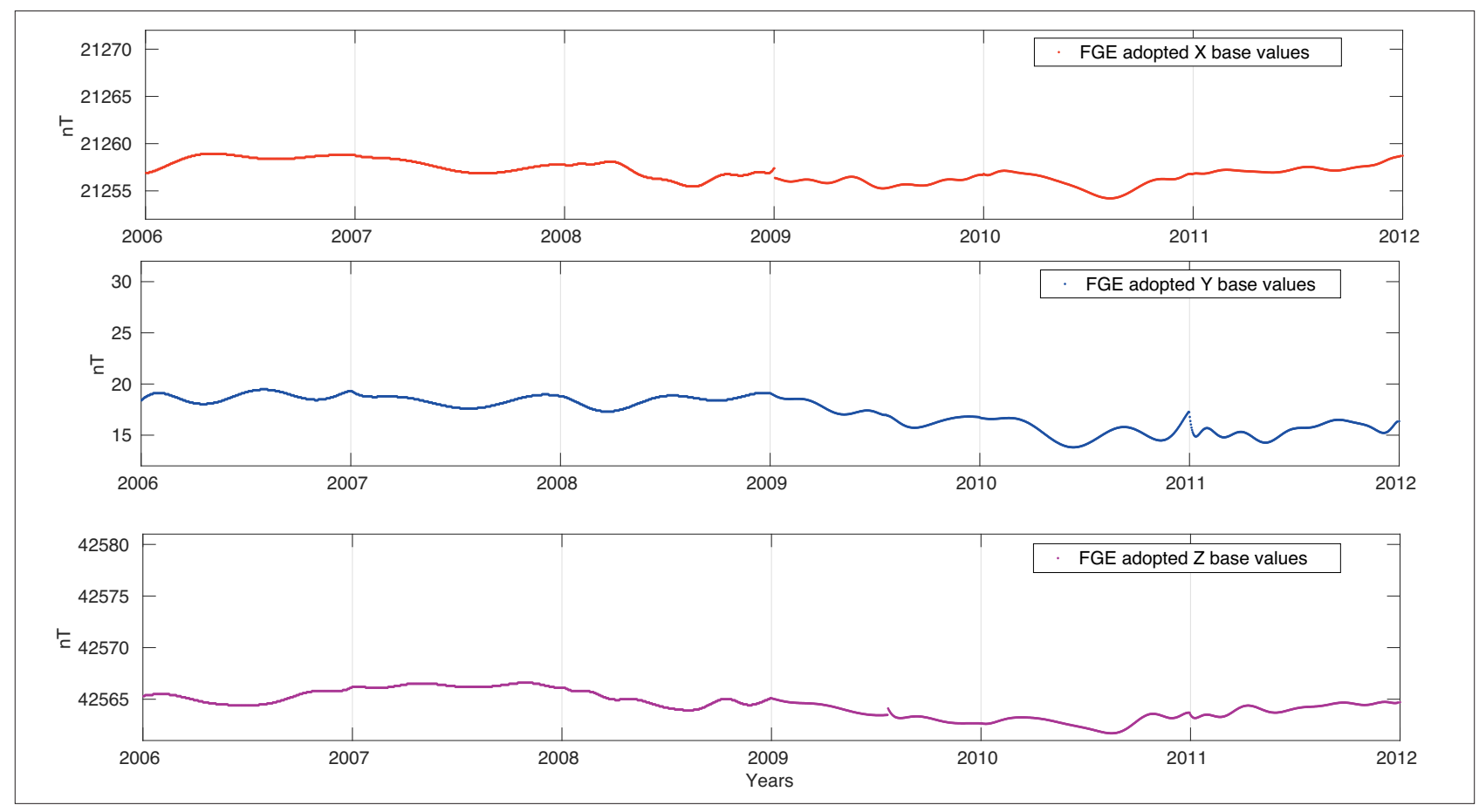

FIGURE 6. The X, Y, Z baselines of the FGE magnetometer 01.01.2006.-31.12.2011.

plained only in terms of the drift due to the temperature effect on the device. According to experiences whith LEMI magnetometer we can exclude the tilt of the pillar as a possible mechanical reason of this observation. A typical annual period of baseline values is clearly seen except of the last two years. We will present later that the only the variation of soil moister has similar behavior. We can see opposite trends in $\mathrm{X}$ and $\mathrm{Z}$ components, this can be a sign of inclination instability. This fact will be evident if we consider that

$$
\begin{aligned}
H & =F^{*} \cos (I) \\
Z & =F^{*} \sin (I) \\
X & =H^{*} \cos (D)
\end{aligned}
$$

where $\mathrm{H}$ is the horizontal and $\mathrm{Z}$ is the vertical component of the totalfield $(\mathrm{F})$ and I is the inclination of the geomagnetic field, $\mathrm{X}$ is the northern component of the horizontal component, and $\mathrm{D}$ is the declination of the geomagnetic field. The difference between $\mathrm{H}$ and $\mathrm{X}$ is a low value because $\mathrm{D}$ was less than $4^{\circ}$ during these years. If the inclination difference between the absolute pillar and the site of variometer is changing, $\mathrm{Z}$ and $\mathrm{X}$ base values are also changing with opposite trends. The ratio of the observed amplitudes of $\mathrm{X}$ and $\mathrm{Z}$ base values is near 2 because the derivate of $\cos (\mathrm{x})$ function is $-\sin (\mathrm{x})$ and the derivate of $\sin (\mathrm{x})$ function is $\cos (\mathrm{x})$, in addition the inclination in our observatory is around $63.5^{\circ}$ so $\mathrm{dX} / \mathrm{dZ}=$ $\sin \left(63.5^{\circ}\right) / \cos \left(63.5^{\circ}\right) \approx 0.895 / 0.446 \approx 2$.

The recorded baseline variation in Figure $3(\mathrm{X}$ and $\mathrm{Z}$ components) accords to the above presented process and ratio. This mathematical model points, that the studied baseline instability might be a systematical geomagnetic mechanism and surely not a random noise.

Our hypothesis is that the variation of an environmental property is the reason of the inclination instabilities in the old variation house. This assumption will be tested in what follows against other possible explanations.

\section{CHARACTERIZATION OF THE GEOMAGNETIC EFFECT AND OF ITS SPATIAL DISTRIBUTION}

Our hypothesis required that we check those phenomena which usually characterized a yearly cycle and that could be the cause of the observed instability. One of the candidate phenomena involves the surfaces of the lake waters near the observatory. As shown in Figure 1, there are two lakes on the Tihany Peninsula: the Inner Lake and the Outer Lake. They are independent lakes, and they have no surface outlet. Lake Balaton constitutes the border of the peninsula. The water level of Lake Balaton is controlled and it is recorded two times a day. We received water level 
records of the Outer Lake, too. In this case, the sampling rate is of one reading per month. There is no water level observation in the case of Inner Lake. In the year 2010 the weather was extremely wet. We expected significantly different behavior of the three lakes described above. This fact gives us a chance to exclude some possible sources of the observed effect, i.e. baseline instability. Figure 4 presents the $\mathrm{Z}$ baseline and the water levels in the period 20062011. The similar behavior of the DIDD baseline and the water level of the Outer Lake is evident. We calculated also the Pearson product-moment correlation coefficient for the presented data sets. The result was 0.86 in case of the water level of the Outer Lake, and of 0.74 in the case of the water level of Lake Balaton. Presently there is no other long-term water level (for instance groundwater) record from the area of the peninsula.

In order to determine the spatial distribution of the effect within the observatory area, we examined the long term behaviour of measurements taken in the different houses. To test measurements taken in the absolute measurements house we compared secular geomagnetic variation observed at Tihany (IAGA code: THY) with that observed at a reference observatory. For this purpose Belsk observatory (IAGA code: BEL), near Warsaw and about 500-600 kilometres away from Tihany, was chosen. The published definitive values of both observatories represent the measured values on the absolute pillar of the observatory located in the absolute house. We calculated the difference of $\mathrm{Z}$ components between the daily means estimated at THY and BEL observatories for the time interval 01.01.2006-31.12.2011. The variation in time of the difference is presented in Figure 5 that shows that the geomagnetic field on the absolute pillar is practically free from the oscillation presented above in Figure 4. Then we took measurements made in a new pavilion. In Figure 6, we plotted the FGE magnetometer adapted baseline for the observatory for the same time interval (Figure 6). This device was installed about 50 meters away from the absolute pillar of the observatory in a new hut. This hut is in the upper and rocky part of the observatory grounds (Figure 2). The difference in elevation between the pillars of the two sites is about ten meters. The long term baseline of the FGE device also presents fluctuations, but they are more attenuated compared to those of the instruments located in the cellar.

The above presented circumstances make clear that the studied effect appears most significantly in the old variation house. Our task is to find the source of the presented phenomenon.

\section{POSSIBLE REASONS OF THE OBSERVED BASELINE INSTABILITY}

\subsection{MAGNETIC PARTICLES (MAGNETITE, MAGHEMITE, HEMATITE AND GOETHITE, $(\alpha-\mathrm{FeOOH})]$ IN THE DEPOSITS}

The volcanic rocks create special circumstances on the Tihany Peninsula. We found magnetite in the in the northern part of the Tihany Peninsula but not in the sediment samples from the observatory grounds, anyway we can not exclude the existence of this mineral there. The magnetite mostly appears in the form of small crystals. Moreover X-ray powder diffraction measurement (XRD) detected several types of clays (illite, kaolinite, smectites) in the samples with a significant percentage. The small particles of different minerals can mark that the typical part of the volcanic minerals in the peninsula are the consequences of weathering and metamorphose processes. The result of the X-ray powder diffraction measurements pointed that the clays of the peninsula could be an important deposit to find an answer to our questions. A sample of clay from the observatory grounds was tested magnetically. We found that the deposit is slightly magnetic so the appearance of detrital remanent magnetization (DRM) as perhaps chemical remanent magnetization (CRM) of the sediment is evident. New X-ray powder diffraction measurements were performed. As a result goethite was detected in the sediment, which is an antiferromagnetic ferrihydrite. After heavy mineral separation XRD measurement detected maghemite, hematite and in the samples of deposits.

The origin of the goethite, maghemite and hematite is mostly due to hydrothermal processes, for instance hot springs. The goethite-hematite phase transformation is well-known [Jiang Z. et al., 2016]. The paleomagnetic studies describe the goethite as a material with an unstable (noisy) behavior. The water content of the goethite can vary in time [Zhou Long et al., 2017].

The above described behavior was studied by Koch et al. [1986], they found that the increasing desorption of water leads to an increase in micro-strain and to an enhanced magnetic coupling between neighboring micro-crystals, giving rise to the so called super-ferromagnetic behavior. This effect was repeatedly studied since then.

In our case the situation is supposedly more complex. We detected the magnetic minerals in the clay which is a well-known natural colloid. In this case the physical 
and chemical properties of colloids could also be important for the exact description. Coagulation, sedimentation, adsorption, and other processes are usually controlled by physical chemistry of the solid/liquid interface. Most models for these processes are based on studies of colloidal systems. In our study several possible processes have not been discussed yet.

\subsection{FURTHER STUDIES TO CHARACTERISE THE BASELINE INSTABILITY}

Figure 4 presents a long term relation between the water saturation of the area and base values. In our case the water level of the Outer Lake is an indicator of the soil moisture of the area because the effect appears only near the variation house. The geological environment shows significant differences also within the area of the observatory. The absolute house was built on a rocky apex of the cone geyser but the variation house was sunk in a clayey area (Figure 2). The geological map marks the interface between the geyserite and a combination of slightly redeposited, weathered material [Budai et al., 1999]. Each of the sediments is perhaps the result of hydrothermal processes so the spatial distribution of different sediments (clay, debris of scoriaceous basalt, etc.) can be variegated. We can suppose that the water saturation of the clay sediment with significant iron-oxide content should be the really important quantity in the case of the studied baseline instability. On the other hand the resistivity of the clayed sediment is also a function of the water saturation. There is not any evidence that the variation of the resistivity could cause a baseline drift. Moreover the existence of a stable DC current near the magnetometers must have another typical geomagnetic marks, i.e. the short term difference of geomagnetic elements would be a function of geomagnetic variation [Csontos, 2012]. The change of the susceptibility and the remanent magnetization of the deposit can be the explanation of the baseline instabilities.

\subsubsection{THE SHORT TERM FLUCTUATIONS OF THE VER- TICAL BASE VALUES AND THE CALCULATED WA- TER LEVEL}

If we measure the effect on the baseline caused by the water saturation of the sediments, we should realize more or less the same short term fluctuations in the independent geomagnetic and soil moisture datasets. We received daily precipitation data from the next village (Aszófó) which is approximately four $\mathrm{km}$ away from the observatory. The water level is a function, to a first approximation, of the cumulated precipitation and the evaporation. This assumption is acceptable in the case of Tihany Peninsula because the other processes (for example underground water inlet and outlet) are attenuated and well balanced [Tóth et al., 2016). The mean value of the monthly evaporation was estimated as a median value of evaporations calculated from the wa-

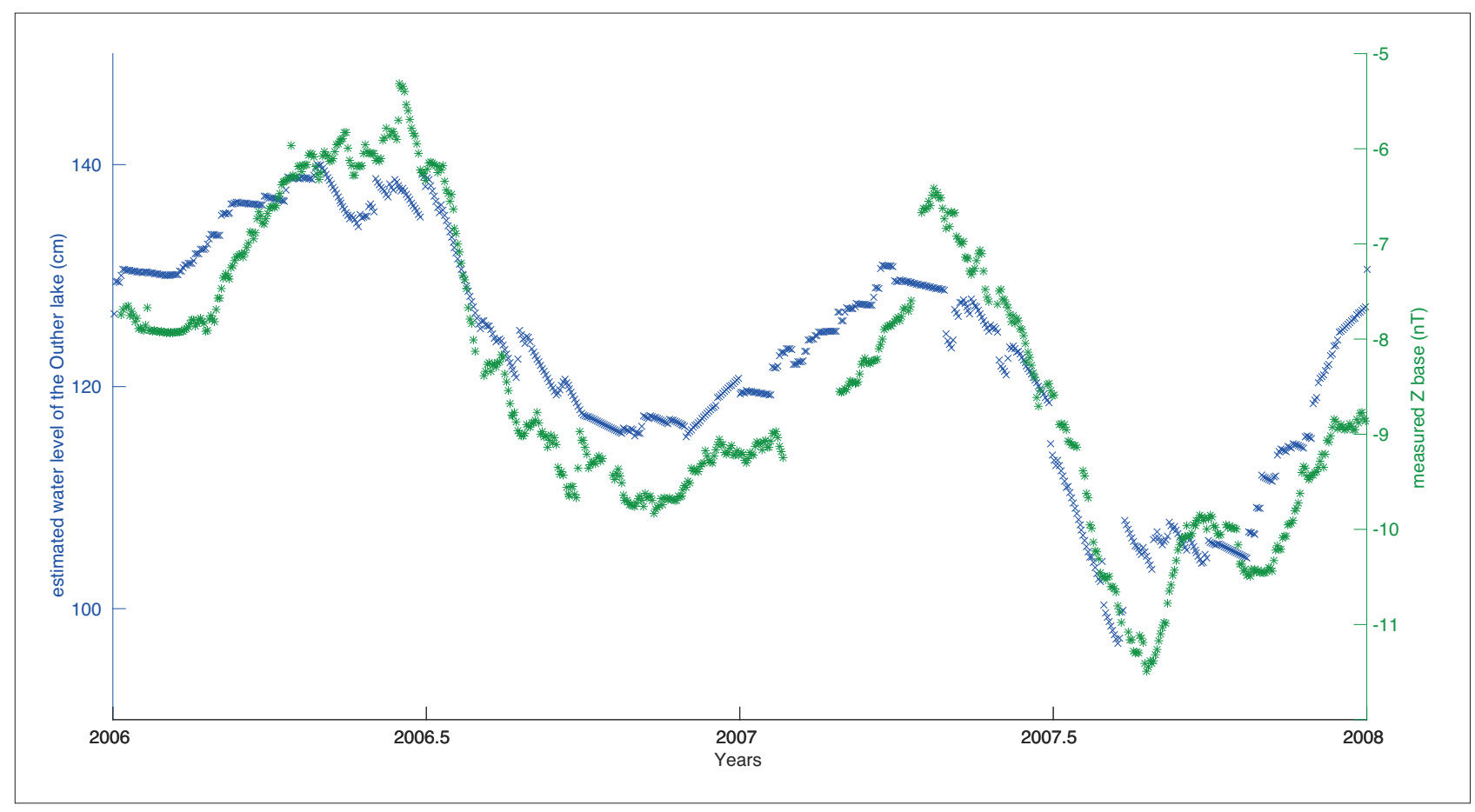

FIGURE 7. Calculated soil moisture and the measured DIDD Z base values ( 01. 01. 2006. - 12. 31 . 2007). 


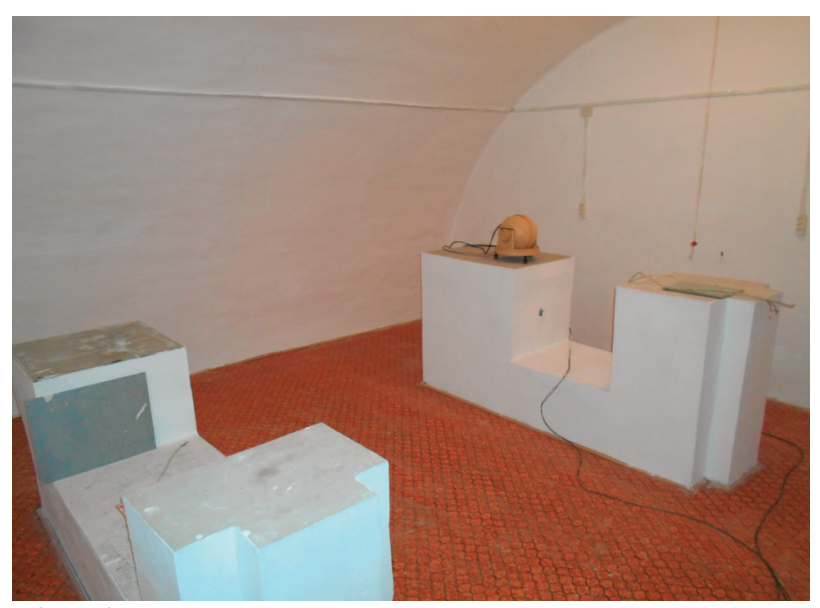

FIGURE 8. The eastern room of the variation house with the sensor of DIDD device.

ter level data of the Outer Lake. We used a six-year-long dataset for this calculation. The difference of the calculated soil moisture and observed water level of the Outer Lake was very stable (within $30 \mathrm{~mm}$ ) during the years of 2006 and 2007.

The plots of the calculated soil moisture and the measured $\mathrm{Z}$ baseline are presented in Figure 7 We can conclude that the shape of the curves of different quantities is similar. We can see that the effect on the base values is delayed. The estimated delay (by applying correlation optimization) is 12 days. The value of Pearson product-moment correlation coefficient was 0.95 in this case. This result clearly demonstrates that
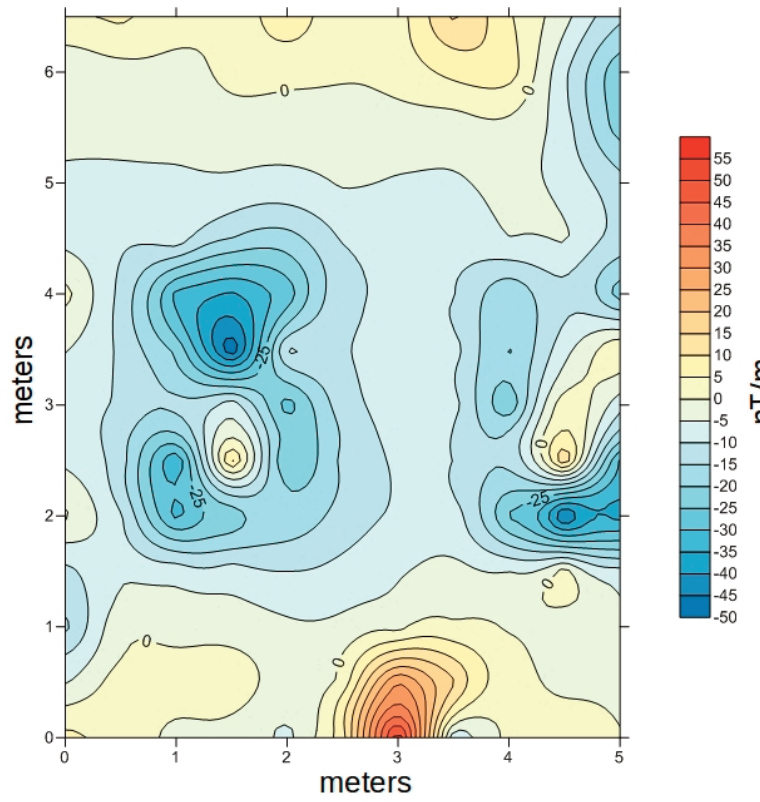

FIGURE 9. Magnetic vertical gradient of total field in the old variation house. the appearance of the precipitation can be the reason of the baseline variation. On the other hand the material which produces the effect is not directly on the surface but mostly at depth.

\subsubsection{THE STRUCTURE AND THE SPATIAL DISTRI- BUTION OF THE CRUSTAL FIELD IN THE OLD VARIATION HOUSE}

In order to provide a more detailed description of the spatial distribution of the geomagnetic field in the old variation house, magnetic surveys were carried out in the cellar on a grid with a spacing of 0.5 meters on different dates. The measurements were performed using an Overhauser gradiometer with an accuracy 0.2 nT. The sensors of the nuclear magnetometer measured the total field at a distance 1 meter from each other along the vertical axis, so the instrument measured the gradient of the total field in vertical direction. The eastern part of the highest room (Figure 8) was surveyed (6.5 meters in $\mathrm{N}-\mathrm{S}$ direction and 5 meters in $\mathrm{E}-\mathrm{W}$ direction).

The map of the vertical gradient is presented in the Figure 9. The zero point of $\mathrm{X}$ and $\mathrm{Y}$ axes corresponds with the corner of the northern and the eastern walls. We can conclude that the highest gradients are near the walls and near the pillars. Concerning the anomalies near the walls, if we suppose that the rocks in the walls are free from magnetic anomalies (as it should be if

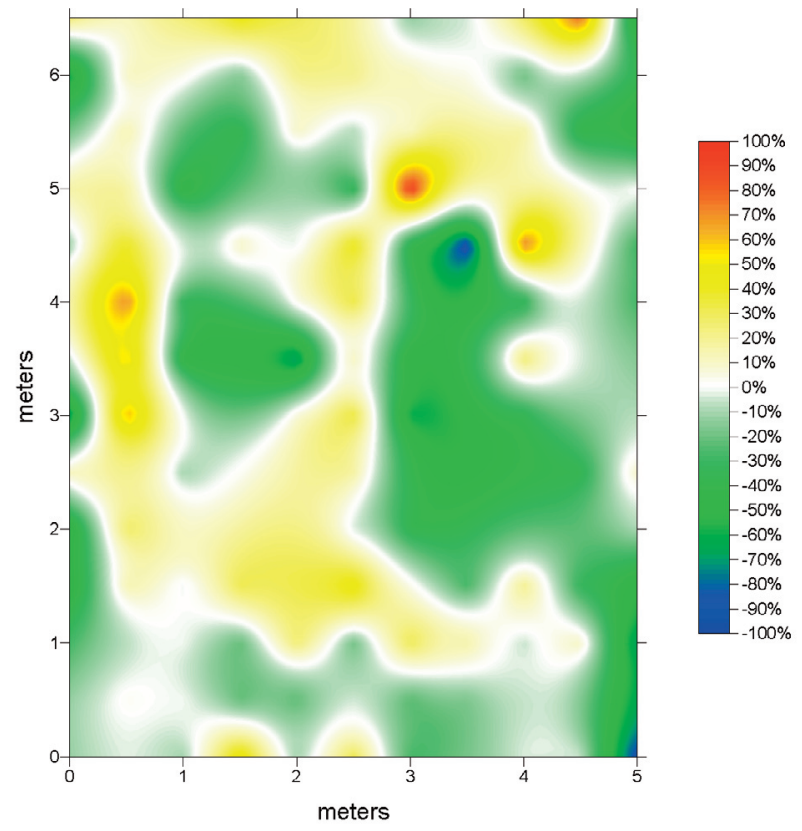

FIGURE 10. The ratio of the vertical gradient measurements in the old variation house surveyed before and after a rainy period. 
during the construction of the observatory rocks were properly chosen), we could interpret the observed high gradients in terms of a not homogeneous presence of magnetic minerals in the sediment. Indeed, the clay (and maybe the geyserite also) around the cellar contains magnetic minerals.

The anomalies around the pillars are caused by the concrete. We took samples from the magnetic part of the pillar and we found small magnetite crystals in it. During the construction work the gravel for the concrete was supposedly bought from the nearest mine of Balaton region. In this case the possibility of magnetic particles in the gravel is high because several areas of the region are infected by volcanic rocks. An important observation is that the anomalies of the pillars did not show dipole structure. The concrete mostly has a reverse magnetization (intensive negative anomalies without positive parts). This can be possible if the pillars have remanent magnetization in the vertical direction. Next to the northern walls we can see big positive anomalies. This can be a sign of induced magnetization.

We repeated the measurement just after a rainy period of the season. The fall, approximately $100 \mathrm{~mm}$, changed the water saturation of the sediment near the wall, but beneath the floor of the cellar the sediment supposedly remained the dry. The distribution of the vertical gradient of the total field significantly changed. We calculated the ratio between the new and the previously measured values, and we expressed the change in percentage. We discarded the values which exceeded 100\%, and other values were presented on a map (Figure 10). Next to the eastern and northern walls the gradients generally decreased. Near the southern wall we can notice weak improvement of the gradient.

We can notice significant changes of the measured vertical gradient in the area of pillars too. The explanation of this result is one of the challenges for the future.

\subsubsection{MEASUREMENTS OF SUSCEPTIBILITY FOR VARIOUS DEGREES OF SOIL HUMIDITY}

We can characterize the magnetic properties of sediments by measuring its magnetic susceptibility. In our case the question was the relation between the magnetic susceptibility of the clayey deposit and its humidity. A sample of clayey sediment was taken near at the old variation house. The XRD measurement

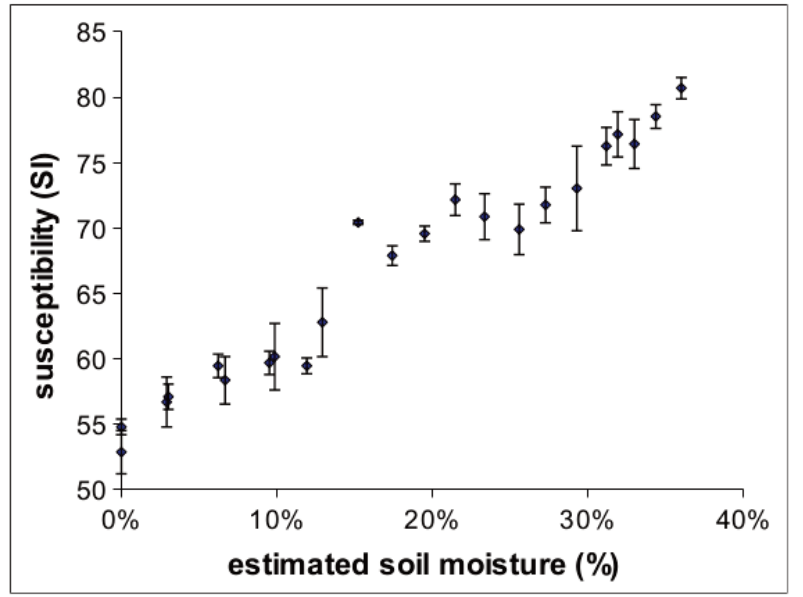

FIGURE 11. Relation between the magnetic susceptibility of clayey sediment and its soil moisture.

from this area detected mostly smectit, calcite and quartz in the soil with goethite (as magnetic iron-hydroxide), hematite (antiferromagnetic), maghemite (ferrimagnetic). The weight of the practically dry sample was 13 grams and we placed it into a plastic box. The original structure of the sediment was not destroyed. The appearance of this sediment is practically a granulated soil.

We measured the susceptibility of the sampled soil with a Bartington MS2 instrument. After three Bartington MS2 readings approximately 0.5 gram water was added to the sample. Minimum two hours later the weight of the sample was measured again with an accuracy of 0.1 gram. In this way we could estimate the soil moisture of the sediment. After the weight measurement susceptibility readings were performed again. After several cycles (when the soil reached approximately 10\% humidity) we dried the sample and we restarted the test. Figure 11 shows the result of the measurements.

The original susceptibility of the soil was relatively high. It is a mark of ferrimagnetic mineral(s) in the sample. The susceptibility increased (more than $50 \%$ ) as a result of added water. The increase of the susceptibility was not continuous but the variation shows mostly linear trend. The mechanism was reversible if we dried the sample. The different behavior of the induced and remanent magnetization was not measured yet.

Maybe the increasing volume of the smectite crystals due to the added water leads to an enhanced magnetic coupling between neighboring micro-crystals of magnetic mineral (i.e. granulated soil becomes more coherent). Perhaps the added water formed an alter- 
native lattice structure in the sediment which gives rise different magnetic states. The final identification of the mechanism will be a challenge for the future.

\subsection{THE BEHAVIOR OF THE BASELINE AND GRADIENT SURVEYS}

The above presented mechanism allows us to suggest a simple model to describe the baseline instability of the old variation house.

We measured the vertical gradient of the total field in the cellar and we found that its intensity and its spatial distribution are not stable. Ordinarily we can assume a practically stable susceptibility under the floor and a changing susceptibility behind the walls of the cellar. The direction of the induced magnetic field is exactly the same as of the total field vector. At this point we have to notice that we can assume a reverse anisotropic remanent magnetization (DRM) too. The remanent crustal field supposedly also changes due to the humidity of the sediment. In this case the changing crustal field (which is the superposition of the remanent and the induced magnetic fields) has a significantly different direction compared to the total field direction. This theory can explain the following facts:

1) The variation of the total field difference between the absolute pillar and DIDD shows only a very slow and attenuated changes (see Figure 4). A possible explanation can be that only the induced magnetization of the floor and the pillar is parallel with the total field vector. But the humidity of the sediment beneath the floor is more or less stable. It has only a very slow and attenuated development in time.

2) The baseline of the vertical (Z) and the horizontal (X) values indicate an unstable crustal field vector which is practically perpendicular to the total field vector, and it lies approximately in the magnetic meridian plane. In this case it would be enough for the explanation of the observed inclination changing if the crustal field instability (Fc) attains \pm 10 nanoteslas (nT). The inclination difference (dI) between the absolute pillar and the pillar of the DIDD will change in this case:

$$
\begin{gathered}
d I=\arctan (F c / F) \approx \arctan (10 n T / 48000 n T) \\
=43 \operatorname{arc~second}
\end{gathered}
$$

Where $\mathrm{F}$ is the mean total intensity value of the geomagnetic field. According to equation 1 and 2 we can calculate the expected baseline drift in $\mathrm{Z}$ component ( $\mathrm{dZ}$ ) and $\mathrm{H}(\approx \mathrm{X})$ component $(\mathrm{dH})$ too:

$$
\begin{aligned}
d Z & =[\sin (I)-\sin (I+d I)]^{*} F \\
d H & =[\cos (I)-\cos (I+d I)]^{*} F
\end{aligned}
$$

In the magnetic latitude of Tihany observatory this instability creates $\pm 4.5 \mathrm{nT}$ baseline drift in $\mathrm{Z}$ component and $\pm 9 \mathrm{nT}$ baseline drift in X component, but this effect is not practically measurable in the total field baseline. The sign of $\mathrm{Z}$ and $\mathrm{X}$ variation is opposite. This model can explain the $\mathrm{Z}$ and $\mathrm{X}$ baseline on Figure 4. The above presented instabilities of the vertical gradients are of the same magnitude. The variation of $Y$ baseline shows that the changing crustal filed has got an eastern component too.

\section{BASELINE CORRECTION}

The above mentioned strong correlation between the baseline and the water level data was sufficient to make a correction. In our model, a linear correlation was assumed between the two quantities. The very rarely observed water level data could be a good source of this correction. We applied the

$$
\mathrm{CoB}_{\text {(corr) }}=\mathrm{CoB}_{\text {(meas) }}-\mathrm{L}^{*} \mathrm{C}_{\text {(comp) }}+\mathrm{R}_{\text {(comp) }}
$$

expression where $\mathrm{CoB}_{\text {(corr) }}$ is the corresponding corrected component of base value, $\mathrm{CoB}_{\text {(meas) }}$ is the measured base value, $\mathrm{L}$ is the water level of the Outer Lake, $\mathrm{C}_{\text {(comp) }}$ is the "water level" coefficient of the actual component and $\mathrm{R}_{\text {(comp) }}$ is difference of the actual component between the pillar and the location of DIDD. $\mathrm{R}_{\text {(comp) }}$ depends on the actual difference between the pillars and the reference frame of DIDD too. We applied numeric optimization in order to find the optimal $\mathrm{C}_{\text {(comp) }}$ values. Our criteria for this optimization was to reach the minimal standard deviation of the corresponding corrected base values.

The coefficients for the components:

$$
\begin{aligned}
& C_{(X)}=0.132 \mathrm{nT} / \mathrm{cm}, R_{(X)}=-43 \mathrm{nT} \\
& C_{(Y)}=-0.151 \mathrm{nT} / \mathrm{cm}, R_{(Y)}=31 \mathrm{nT} \\
& C_{(\mathrm{Z})}=-0.071 \mathrm{nT} / \mathrm{cm}, \mathrm{R}_{(\mathrm{Z})}=17 \mathrm{nT}
\end{aligned}
$$

The result of baseline correction is presented in Figure 12. The ratio between $\mathrm{C}(\mathrm{X})$ and $\mathrm{C}(\mathrm{Z})$ is a consequence of the actual inclination in Tihany observatory. In the case of the Y component other effects are also possible, 

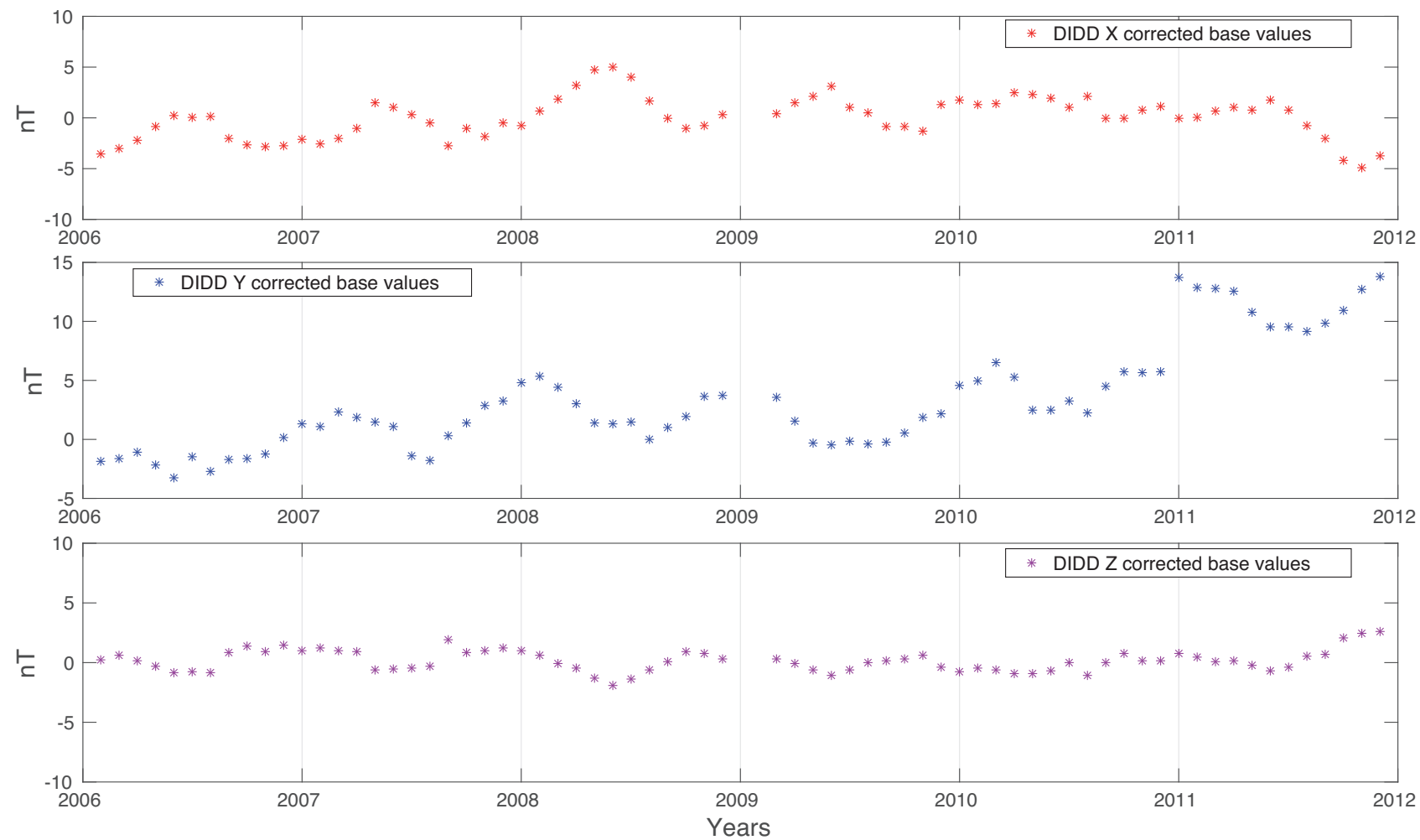

FIGURE 12. The monthly means of corrected DIDD X, Y, Z base values 01.2006.-12.2011.

i.e. temperature effect on the coil system and/or pillar or instrument tilt.

\section{CONCLUSIONS}

The presented instability on the base values appears especially in measurements made in the old variation house of the Tihany observatory. In fact, the secular variation of Tihany observatory that is based on recordings made in the absolute measurements house is practically free from this phenomenon as shown from comparisons with Belsk observatory. Effects on magnetometers as temperature effects or sensor tilt, cannot be excluded, but they are not suitable to characterize the anomalous behavior of the base values examined in this study.

According to all indicators, we expect magnetic sediment around the old variation house which was built at an interface of a clayey material and geyserite. Both of the sediments can be a deposit resulting from the earlier hydrothermal processes of Tihany Peninsula. X-ray powder diffraction measurements detected magnetic minerals in the clay samples. This fact and the presented measurements make it possible to expect that sediment around the variation house has an anisotropic remanent magnetization (DRM). The susceptibility and the remanent magnetization of the sediment is a function of the water saturation of the deposit. This behavior of the sediment can be the result of the physical properties of magnetic minerals and probably of the clay as well. The final identification of the effect will be a challenge for the future.

We could identify the influence of a changing geomagnetic gradient in reference to the baseline and the spatial distribution of a vertical gradient of total field value. The susceptibility measurements verified significant instability of magnetic property of the soil. A simple model for the geomagnetic processes was presented. Corrections based on the observed quantities were also performed. The corrected baseline of DIDD shows that the instrument had a more or less stable baseline in the case of $\mathrm{X}$ and $\mathrm{Z}$ components.

In this study we investigated a phenomenon which was not described before in geomagnetic observatory practice.

Acknowledgements. László Hegymegi and Balázs Heilig are thanked for their useful remarks. We greatfully anknowledge József Vers for supplying the water level data and Jenő Hamar for the precipitation dataset. For all the support we got for in- 
formatical and technical solutions, we thank László Merényi and László Szabados. Special thank goes to Tamás Lipovics and László Lenkey for the valuable discussions -and for the field works. The results presented in this paper rely on data collected at magnetic observatories. We thank the national institutes that support them and INTERMAGNET for promoting high standards of magnetic observatory practice. I greatfully anknowledge also Brian Lassige and the anonymous reviewers for the corrections of the manuscript.

\section{REFERENCES}

Annual Reports Of Tihany Geophysical Observatory 19551987

Barta Gy. (1956) A Tihanyi geofizikai obszervatórium Geofızikai Közlemények V. Kötet 2.

Bender 0., Varrók K., Reményi Gy. (1966): A tihanyi obszervatórium környékén végzett földtani, földmágneses és gravitációs vizsgálatok. Geofizikai Közlemények XV. Kötet, 1-4 szám 83-93. old.

Budai T., Csillag G., Dudko A. and Koloszár L. (szerk.) 1999: A Balaton-felvidék földtani térképe. $M=1: 50$ 000. - A Magyar Állami Földtani Intézet kiadványa

Csontos A. (2012): Methods for measuring the gradient of the magnetic field using standard observatory instrumentation, Proceedings of the XVth IAGA Workshop on Geomagnetic Observatory Instruments, Data Acquisition, and Processing, pp. 38-41, San Fernando, Spain.

Csontos A., Hegymegi L., Heilig B., Kovács P., Merényi L., Szabó Z. (2007): 50 Years of History of the Tihany Geophysical Observatory. Publs. Inst. Geophys. Pol. Acad. Sc., C-99 (398).

INTERMAGNET CD 1991-2012

Jankowski J., C. Sucksdorff: Guide for magnetic measurements and observatory practice, IAGA, Warsaw, Poland, 1996. Koch C.J.W., Madsen M.B., Mørup S., Christiansen G., Gerward L., Villadsen J. (1986) Effect of heating on microcrystalline synthetic goethite. Clays and Clay Minerals, 34, 17-24.

Lipovics T., Csontos A., Lenkey L. (2004) Preliminary results of geophysical studies over the Tihany Volcano at the Tihany Peninsula, Hungary. Abstract volume of the Second International Maar Conference, 21-26 September 2004, Lajosmizse/Kecskemét, Hungary. Occasional papers of the Geological Instute of Hungary, Volume 203. 70 pp.

Lóczy, L.i., (1913) A Balaton környékének geológiai képződményei és ezeknek vidékek szerinti telepedése (Geological units of the Balaton area and their stratigraphy [in Hungarian]). In: Lóczy, L.i. (Ed.). A Balaton tudományos tanulmányozásának eredményei (New results of the scientic research of the Balaton [in Hungarian]). Magyar Királyi Földtani Intézet [Royal Hungarian Geological Institute], Budapest, 617 pp.

Németh, K., Martin, U., and Harangi Sz. (2001) Miocene phreatomagmatic volcanism at Tihany (Pannonian Basin, Hungary). Journal of Volcanology and Geothermal Research, 111: 111-135

Németh, K., Martin, U. and Harangi, Sz. (1999): Miocene maar/diatreme volcanism at the Tihany Peninsula (Pannonian Basin): The Tihany Volcano. - Acta Geologica Hungarica 42, 349-377

Tóth Á. Tímea Havril, Szilvia Simon, Attila Galsa, Fernando A. Monteiro Santos, Imre Müller, Judit MádlSzőnyi (2016): Groundwater flow pattern and related environmental phenomena in complex geologic setting based on integrated model construction, Journal of Hydrology 539 pp. 330-344

Wienert K. A. (1970) Notes on geomagnetic observatory and survey practice, Unesco, Paris, 217 pp.

Zhaoxia Jiang, Qingsong Liu, Mark J. Dekkers, Vidal Barrón, José Torrent, Andrew P. Roberts (2016): Control of Earth-like magnetic fields on the transformation of ferrihydrite to hematite and goethite. Sci. Rep. 6, 30395; doi: 10.1038/srep30395 .

Zhou Long, Xiu Fangyuan, Qiu Meng, Xia Shuwei, Yu Liangmin (2017): The adsorption and dissociation of water molecule on goethite (010) surface: A DFT approach, Applied Surface Science 392 pp. 760-767.

*CORRESPONDING AUTHOR: András CSONTOS,

Mining and Geological Survey of Hungary,

Budapest, Hungary

email: csontos.andras@mbfsz.gov.hu 